\section{Triple-Band Planar Dipole Antenna for Omnidirectional Radiation}

\section{Alibakhshikenari, B. S. Virdee, E. Limiti}

This Letter presents a compact triple-band dipole antenna that radiates omnidirectionally. The antenna is a T-shaped structure that is excited through a vertical feedline. Located under the horizontal rectangular patch are two $\lambda / 2$ long meander-line stubs symmetrically interfaced to the feedline. On the bottom side of the substrate is a trident shaped ground-plane structure located under the T-shaped radiator. The proposed configuration is essentially composed of three radiating elements, which has a small footprint of $19 \times 16 \mathrm{~mm}^{2}$ on a $0.8 \mathrm{~mm}$ thick substrate. Regions of enhanced impedance matching are realized between $0.5-2.69 \mathrm{GHz}, 3.2-4.44 \mathrm{GHz}$ and $4.82-6.6 \mathrm{GHz}$ covering major portions of $\mathrm{L}, \mathrm{S}$ and $\mathrm{C}$-bands. It is shown by reducing the gap between the meander lines stub and rectangular patch reduces results in increased gain performance. Measured results confirm the antenna exhibits omnidirectional radiation with enhanced impedance match at $1.5,4$ and $5.4 \mathrm{GHz}$ with corresponding average gain of $1.6 \mathrm{dBi}, 3.4 \mathrm{dBi}$ and $3 \mathrm{dBi}$, respectively.

Introduction: Nowadays more and more wireless communication systems are working simultaneously at multiple bands, e.g. Global Positioning System (GPS) operates at $1.227 \mathrm{GHz} \& 1.575 \mathrm{GHz}$ bands, and Worldwide Interoperability for Microwave Access (WiMAX) operates at $2.6 \mathrm{GHz}, 3.5 \mathrm{GHz} \& 5.5 \mathrm{GHz}$ bands. This therefore necessitates the need for multiband antennas, which can be designed using several existing methods including employing: (i) multimode monopoles [1], [2]; (ii) microstrip patches embedded with slots [3], [4]; and (iii) metamaterial technologies [5]. Former two types antennas radiate bidirectionally and have relatively low directivity and gain characteristics. Although the latter type of antenna is highly compact it radiates unidirectionally and suffers from low radiation efficiency.

In this Letter, a compact planar dipole antenna is proposed that employs three radiation elements to implement a multimode antenna that radiates energy omnidirectionally in its three frequency bands. The impedance bandwidth measured (for $\mathrm{S}_{11} \leq-10 \mathrm{~dB}$ ) of the proposed antenna is $2.19 \mathrm{GHz}(0.5-2.69 \mathrm{GHz}), 1.32 \mathrm{GHz}(3.2-4.44 \mathrm{GHz})$, and $1.78 \mathrm{GHz}(4.82-6.6 \mathrm{GHz})$. The average gain of the antenna in the three bands is $1.6 \mathrm{dBi}, 3.4 \mathrm{dBi}$ and $3 \mathrm{dBi}$, respectively.

Antenna Structure: The proposed triple-band dipole antenna is composed of a T-shaped geometry comprising a narrow horizontal rectangular patch that is excited through a vertical feedline, as shown in Fig. 1. The feedline is interconnected to two $\lambda / 2$ long meander-line stubs symmetrically located just below the rectangular patch. On the opposite side of the substrate is printed a trident shaped ground-plane structure which is located below the T-shaped radiator. The antenna was fabricated on $0.8 \mathrm{~mm}$ thick Rogers RT/Duroid5880 substrate having a dielectric constant of 2.2 and a loss-tangent of $\tan \delta=9 \times 10^{-4}$. The optimized dimensions of the proposed antenna are given in Table I.

Analysis shows the characteristics of the proposed antenna is affected by several key-parameters, i.e. the length/width of the rectangular stub, and length/width of the meandered elements. Simulated return-loss of the proposed antenna as a function of the length/width of the rectangular radiator is shown in Fig. 2(a). It can be observed that with an increase in length (L), the magnitudes of the three impedance band improve significantly, however the first and third bands shift towards lower frequency. Fig. 2(b) shows that with an increase in length of the meander lines $(\mathrm{Lm})$ there is negligible effect on the magnitude of the first and third impedance bands; however the impedance match of the second band improves significantly. Fig. 2 shows the width of rectangular stub $\left(\mathrm{W}_{1}\right)$ and width of meander lines $\left(\mathrm{L}_{5}=\mathrm{W}_{2}\right)$ also have major influence on the impedance matching properties. Increase in stub width $\left(\mathrm{W}_{1}\right)$ greatly improves the impedance match in all three bands, whereas by increasing the width of the meander line only improves the impedance match of the second band.

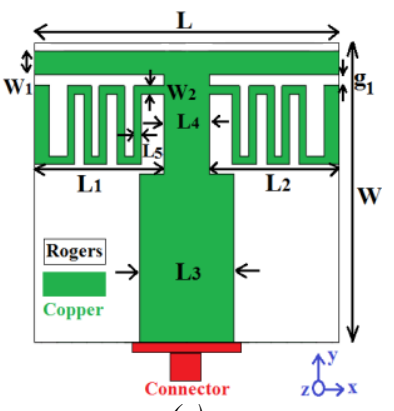

(a)

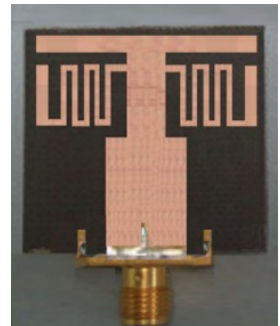

(b)

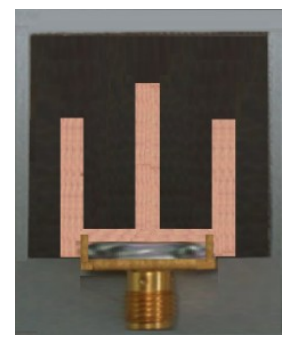

(c)

Fig. 1 Geometry of the proposed Triple-band antenna

a Simulated layout

$b$ Fabricated prototype (front view)

c Fabricated prototype (back view)

Table 1. Parameters defining the antenna. All dimensions given are in millimetres.

\begin{tabular}{|c|c|c|c|c|c|c|c|c|}
\hline $\mathrm{L}$ & $\mathrm{L}_{1}=\mathrm{L}_{2}$ & $\mathrm{~L}_{3}$ & $\mathrm{~L}_{4}$ & $\mathrm{~L}_{5}=\mathrm{W}_{2}$ & $\mathrm{~L}_{\mathrm{m}}$ & $\mathrm{W}$ & $\mathrm{W}_{1}$ & $\mathrm{~g}_{1}$ \\
\hline 19 & 8 & 6.5 & 3 & 0.7 & 30 & 16 & 1.5 & 0.85 \\
\hline
\end{tabular}

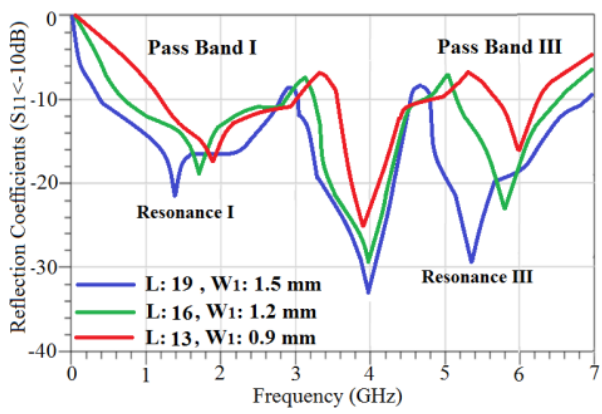

$a$

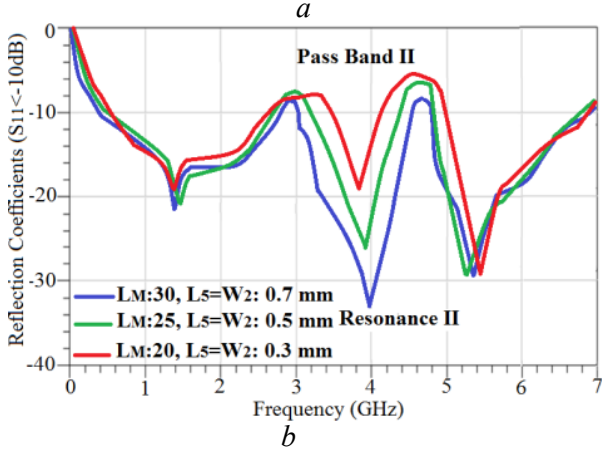

Fig. 2 Parametric study of rectangular stub and meander lines

Simulated \& measured return-loss response is shown in Fig. 3. There is excellent agreement between the simulated and measured results. Small discrepancies between measured and simulated result is attributed to manufacturing tolerance and quality of RF-connection. The measured impedance bandwidth for $\mathrm{S}_{11}<-10 \mathrm{~dB}$ is $2.19 \mathrm{GHz}(0.5-2.69$ $\mathrm{GHz}), 1.32 \mathrm{GHz}(3.2-4.44 \mathrm{GHz})$, and $1.78 \mathrm{GHz}(4.82-6.6 \mathrm{GHz})$. 


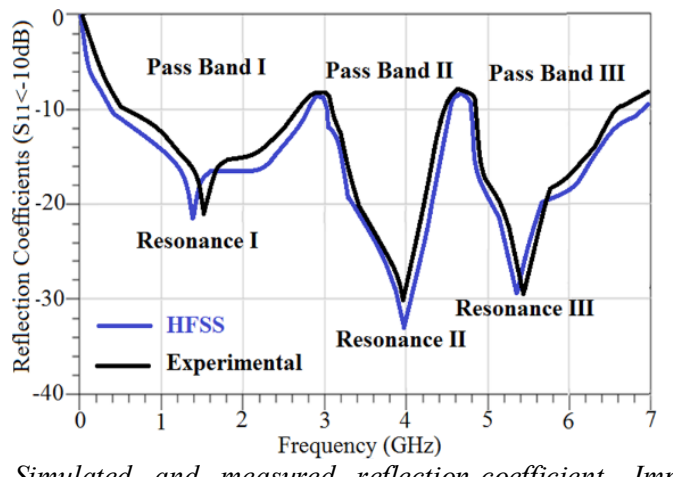

Fig. 3 Simulated and measured reflection-coefficient. Impedance bandwidth is defined for $S_{11}<-10 \mathrm{~dB}$

Surface current density over the proposed antenna at the center frequency of the three bands, shown in Fig. 4, was determined using High Frequency Structure Simulator (HFSS ${ }^{\mathrm{TM}}$ ). The current is concentrated strongly over the meander line at 1.5 and $5.4 \mathrm{GHz}$, indicating the meander lines influence the first and third bands. Whereas at $4 \mathrm{GHz}$ the surface current is strongly concentrated over the rectangular stub, which indicates the rectangular stub has a predominant influence on the second resonant band.

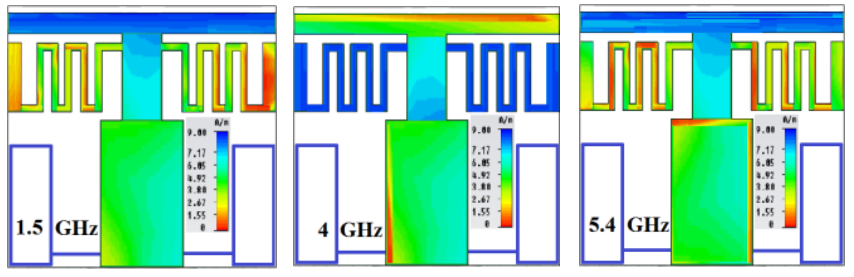

Fig. 4 Surface current density distributions at resonant frequencies

HFSS $^{\text {TM }}$ was used to simulate the co- and cross-polarization radiation patterns of the triple-band antenna. Radiation patterns of the proposed antenna were measured in an anechoic chamber using standard antenna measurement system. The simulated and measured radiation patterns at the antenna's resonant frequencies are shown in Fig. 5. There is excellent correlation between the simulated and measured results. The slight difference is attributed to measurement and alignment errors. The results show the antenna to radiate omnidirectional with crosspolarization better than $5 \mathrm{dBi}$ down over its three bands.

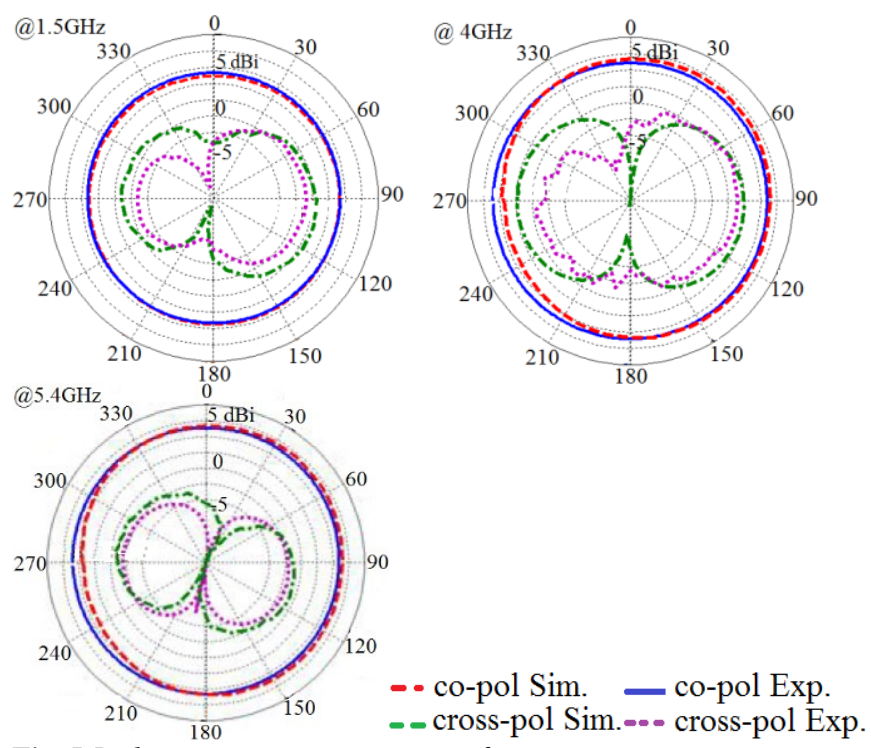

Fig. 5 Radiation patterns at resonance frequencies

Simulated and measured gain response of the triple-band antenna over its operating bands is shown in Fig. 6. The average gain of the antenna in the three bands is $1.6 \mathrm{dBi}, 3.4 \mathrm{dBi}$ and $3 \mathrm{dBi}$, respectively. The gain is high in the higher frequency band. This is because of the increased effective area of the antenna from shorter wavelengths. It was found that by increasing the gap space $\left(\mathrm{g}_{1}\right)$ between the radiation elements, i.e. rectangular raditor and symmetrical meandered lines, the antenna gain increases. The antenna's radiation characteristics are summarized in Table II.

Table 2. Measured radiation characteristics

\begin{tabular}{|c|c|c|c|c|c|}
\hline Frequency $(\mathrm{GHz})$ & 0.5 & 1.5 & 4 & $\mathbf{5 . 4}$ & 6.6 \\
\hline Gain $(\mathrm{dBi})$ & 0.4 & 1.6 & 3.7 & $\mathbf{4}$ & 2.9 \\
\hline Efficiency $(\%)$ & 15 & 41 & 78 & $\mathbf{8 3}$ & 65 \\
\hline
\end{tabular}

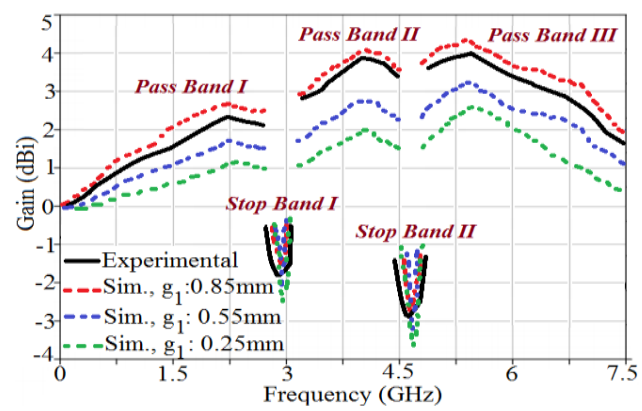

Fig. 6 Gain response of the triple band antenna, and the affect of gap space (g1) on the gain

Conclusion: A compact $\left(19 \times 16 \times 0.8 \mathrm{~mm}^{3}\right)$ dipole antenna design is shown to radiate omnidirectionally over its triple-band. The three independent resonant bands were generated using a T-shaped structure incorporating two $\lambda / 2$ long meander-lines, which are symmetrically excited through the common feedline. Measured results confirm the antenna radiates energy omnidirectionally, and has average gain at the three bands of $1.6 \mathrm{dBi}(0.5-2.69 \mathrm{GHz}), 3.4 \mathrm{dBi}(3.2-4.44 \mathrm{GHz})$ and 3 $\mathrm{dBi}(4.82-6.6 \mathrm{GHz})$. Furthermore, the structure of the proposed antenna is straightforward and simple to design, manufacture and incorporate within any $\mathrm{RF} /$ microwave communications system.

M. Alibakhshikenari*, E. Limiti (Electronics Engineering Department, University of Rome "Tor Vergata", Via del Politecnico 1, 00133 Rome -ITALY,*alibakhshikenari@ing.uniroma2.it)

B. S. Virdee (London Metropolitan University, Center for Communications Technology, School of Computing \& Digital Media, London N7 8DB, UK)

\section{References}

1. Sun, X. L., S. W. Cheung, and T. I. Yuk, "A compact monopole antenna for WLAN applications," Microwave and Optical Technology Letters 56 (2), 2014, pp. 469-475

2. Lin, C.-C., E.-Z. Yu, and C.-Y. Huang, "Dual-band rhombus slot antenna fed by CPW for WLAN applications," Antennas \& Wireless Propagation Letters, IEEE 11, 2012, pp. 362-364

3. Xu, P., Z-H. Yan, and C. Wang, "Multi-band modified fork-shaped monopole antenna with dual L-shaped parasitic plane," Electronics letters 47 (6), 2011, pp. 364-365

4. Lu, J.-H., and Y.-Y. Lee, "Planar compact triple-band monopole antenna for IEEE $802.16 \mathrm{~m}$ worldwide interoperability for microwave access system," IET Microwaves, Antennas \& Propagation, 7 (13), 2013, pp. 1045-1054

5. Yan, S., Soh, P. J., Vandenbosch, G. A. E., "Compact All-Textile Dual-Band Antenna Loaded With Metamaterial-Inspired Structure," IEEE Antennas and Wireless Propagation Letters, vol. 14, 2015, pp. 1486-1489. 